\title{
Instituciones microfinancieras y cajas de ahorro en Santo Tomás Hueyotlipan, Puebla
}

\section{Microfinance institutions and savings banks in the town of Santo Tomás Hueyotlipan, Puebla}

\author{
Kristiano Raccanello* \\ Gerardo Roldán-Bravo**
}

\begin{abstract}
The sparse presence of formal financial intermediaries in rural mexican towns encourages people to rely on rotating savings and credit associations (rosca's), moneylenders and borrowings from relatives/friends. Savings banks, based on the community's social capital, turned out to be a feasible alternative for traditional informal finance. This paper, based on a sample drawn in the town of Santo Tomás Hueyotlipan (Puebla, Mexico), examines the participation of people in informal savings banks and their interaction with other informal financial intermediaries. The probit model estimates show that membership is strongly linked to savings attracting people who neither resort to rosca's nor borrow from moneylenders or relatives/friends.
\end{abstract}

Keywords: savings banks, informal finance, rural finance, microfinance, Mexico.

\section{Resumen}

La exigua presencia de los intermediarios financieros formales en los municipios rurales mexicanos impulsa el uso de tandas y solicitud de dinero a prestamistas, familiares o amigos. Las cajas de ahorro constituyen una alternativa a estos métodos tradicionales y aprovechan el capital social comunitario. Esta investigación, fundamentado en una muestra realizada en el municipio de Santo Tomás Hueyotlipan (Puebla, México), analiza los factores que impulsan la participación en las cajas de ahorro informales y su interacción con otros intermediarios financieros informales. Los resultados del modelo probit indican que la participación responde a la posibilidad de poder ahorrar atrayendo a aquellos individuos que no utilizan tandas, prestamistas o deudas con familiares o amigos.

Palabras clave: cajas de ahorro, finanzas informales, finanzas rurales, microfinanzas, México.

\footnotetext{
* Universidad de las Américas Puebla, México. Correo-e: kristiano.raccanello@udlap.mx

** Investigador independiente. Correo-e: groldan@hotmail.com
} 


\section{Introducción}

Durante las últimas dos décadas, los resultados y alcances del Grameen Bank (Yunus, 2003) han convertido a las microfinanzas en una de las herramientas más importantes para el combate a la pobreza a través del financiamiento de micro proyectos productivos. Esta estrategia, asociada a un mayor desarrollo económico a nivel comunitario y con un mayor empoderamiento por parte de las mujeres, ha sido promocionada y sigue siendo impulsada por parte del Banco Mundial y del Banco Interamericano de Desarrollo entre otras organizaciones internacionales. El mérito de los esquemas microfinancieros consiste en permitir el acceso a los servicios de ahorro y crédito a un segmento excluido por parte del sector financiero formal y proporcionar una fuente alternativa de recursos a las tradicionales fuentes de financiamiento como son los prestamistas y las redes de ayuda mutua conformadas por familiares y amigos en primera instancia. Aun cuando existen algunos estudios que señalan las limitaciones y critican los esquemas microfinancieros (Bateman, 2010), sobre todo para el caso de México, los estudios en torno a este sector son todavía escasos. El objetivo de esta investigación es contribuir a cerrar parcialmente esta brecha de conocimiento analizando si las cajas de ahorro informales atraen a aquellos individuos que utilizan las tandas y los préstamos por parte de familiares o amigos y prestamistas.

Considerando la baja penetración del sector financiero formal en las áreas rurales de México, este trabajo se realizó en la localidad rural de Santo Tomás Hueyotlipan (Puebla) donde, a sabiendas de la existencia de al menos dos cajas de ahorro informales, se levantó una muestra aleatoria sistemática de 250 personas. Los resultados del modelo probit permitieron determinar los factores relacionados con la participación de los individuos en las cajas de ahorro informales en el entorno rural, y aclararon el vínculo entre éstas y los préstamos por parte de los familiares o amigos, los prestamistas y las tandas.

En la primera sección del trabajo se presenta un breve panorama del acceso al financiamiento en las zonas rurales de México, para sucesivamente contextualizar (segunda sección) el rol de la sociedad civil en la provisión de recursos financieros a través de organizaciones com unitarias. La tercera sección describe las fuentes de recursos que se utilizan en las zonas rurales y los beneficios de los esquemas microfinancieros. La información en torno al proceso de aplicación de la encuesta, así como la metodología econométrica y la interpretación de los resultados se presentan en la cuarta sección. Finalmente, la última sección concluye el trabajo. 


\section{Zonas rurales y acceso al sector financiero formal}

En México, durante el 2006, 40.1\% de la población en las zonas rurales se encontraba por debajo de la línea de pobreza y $16.1 \%$ por debajo de la línea de indigencia (Klein, 2009). Estos datos, que a excepción de 1996 presentan una tendencia a la baja, contrastan con los niveles nacionales (31.7 y $8.7 \%$, respectivamente) indicando que la pobreza en las zonas rurales del país es particularmente aguda.

Alpízar et al. (2006b), con los datos de la Encuesta Nacional sobre Niveles de Vida de los Hogares 2002 (Ennvih-2002), encontraron que las viviendas ubicadas en las zonas rurales, respecto a los que se encuentran en las zonas urbanas, muestran una menor educación del jefe del hogar (6.2 ańos frente a 8.8 años), se ocupan en menor medida en el sector formal (18.5 frente a 48\%), generalmente optando por el autoempleo (52.9 frente a 39.1\%). De la misma forma, los hogares en las zonas rurales casi no tienen acceso a los servicios financieros formales.

Para el caso mexicano la falta de acceso al crédito formal en las zonas rurales es endémica. En el 2002, 64.2\% de los hogares rurales no tenía acceso a un crédito (formal o informal), en contraposición a $47.7 \%$ de los hogares en las zonas urbanas (Alpízar et al., 2006b). Para el mismo año, Tejerina y Westley (2007) reportan que, a nivel rural, el sector financiero informal respecto al formal todavía proporcionaba la mayor parte del crédito (17.4 frente a 3.3\%) y casi el mismo porcentaje en cuanto al ahorro (7.8 contra $8.4 \%)$.

La falta de servicios financieros formales puede asociarse a problemas de acceso y de uso. El Primer reporte de inclusión financiera publicado por la Comisión Nacional Bancaria y de Valores (CNBv, 2009) indica que $64.55 \%$ de todos los municipios del país no cuenta con ninguna sucursal bancaria. De acuerdo al tipo de municipio, la falta de acceso al mercado financiero formal atañe particularmente a los denominados como rurales (población inferior a los 5,000 habitantes) y en transición (5,001-15,000 habitantes) en los cuales la falta de sucursales alcanza $96 \%$ y $79 \%$ respectivamente. Referente a los indicadores de uso (por cada 1,000 adultos), los municipios rurales y en transición, respecto a los municipios catalogados como urbanos (50,001-300,000 habitantes) muestran un importante rezago en cuanto al número de cuentas de ahorros y de cheques, tarjetas de crédito y de débito (CNBv, 2009).

\section{Antecedentes de las finanzas rurales}

Durante las décadas de los sesenta y los setenta, la baja penetración de la banca comercial y el uso de mecanismos financieros informales de alto 
costo por parte de la población rural motivaron la intervención de la banca de desarrollo para proporcionar una mayor oferta de servicios financieros (Adams et al., 1984). La intervención se llevó a cabo a través de la oferta de financiamiento a tasas de interés preferenciales dirigidas hacia inversiones que expost facto resultaron poco rentables y fomentaron una cultura de no-repago debido a que las instituciones a cargo de los programas no se preocupaban de cobrar los préstamos (Conning y Udry, 2005). Por un lado, esta estrategia desincentivó la entrada de las instituciones financieras comerciales y por otro, resultó insostenible en el largo plazo (Nagarajan y Meyer, 2005). El fracaso del viejo paradigma de las finanzas rurales se fundamentó en la subestimación de los problemas inherentes a la oferta de créditos en estas zonas (González-Vega, 1998); de este modo, el intento de proveer una alternativa formal a las fuentes informales preexistentes resultó ser ineficiente y con un alcance limitado, que fue aprovechado por el sector informal (Adams, et al., 1984; Bell, 1990; Binswanger y Khandker, 1992). Frente a la inefectividad de estas estrategias se redujeron los recursos canalizados a través de la banca de desarrollo pero, al permanecer las fallas de mercado conjuntamente con la ausencia de la banca comercial, la caída de la oferta de recursos y servicios financieros en las zonas rurales fue una consecuencia natural (Bouquet, 2007).

Los problemas inherentes al viejo paradigma obligaron a replantear el objetivo de proporcionar los servicios financieros en las zonas rurales, esta vez enfocándose en la cobertura y el impacto para la reducción de la pobreza. En particular, a pesar de reconocer la importancia de la disponibilidad de recursos para el desarrollo, en el viejo paradigma las instituciones aún no revestían particular importancia. No es hasta comienzo de la década de los setentas que éstas comienzan a tomar un rol específico (McKinnon, 1973; Shaw, 1973). Casi simultáneamente, a mediados de la década en el Este de Asia, comienzan a difundirse las entidades microfinancieras. Estos esquemas se fundamentan en organizaciones no gubernamentales que otorgan pequeños préstamos con base en la responsabilidad solidaria (Yunus, 2003).

Él éxito de las instituciones microfinancieras y las lecciones impartidas por el paradigma anterior desde finales de la década de los ochentas contribuyeron a plasmar el nuevo paradigma de las finanzas rurales. Esta nueva visión reconoce que también los pobres ahorran (Rutherford, 2000) y que los servicios financieros están basados en las interacciones de mercado (Nagarajan y Meyer, 2005) según los principios de cobertura, sostenibilidad e impacto (Ledgerwood, 1999; Zeller y Meyer 2002).

En México, la presencia del nuevo paradigma se hizo evidente a finales de la década de los ochentas, al reestructurarse la principal institución de 
la banca de desarrollo agropecuaria (Banrural) que a pesar de tener una buena cobertura, mostraba elevadas ineficiencias. Desde finales de la década de los noventas, y durante la siguiente, se dieron ajustes en el marco legislativo en materia bancaria que, no obstante, privilegiaron más los aspectos regulatorios que el fomento a la intermediación (Bouquet, 2007).

A pesar de las ventajas en cuanto a empoderamiento, reducción de la pobreza y canalización de los recursos (Zapata-Martelo et al., 2003), el sector de las microfinanzas en México presenta un atraso respecto a otros países de América Latina; debido a la falta de intermediarios, más no de recursos, este vacío se está colmando con la entrada de nuevas, aunque inexpertas, organizaciones (Cotler, 2003; Alpízar y González-Vega, 2006a; Gómez-Soto y González-Vega, 2006) que comparten el mercado con otras orientadas hacia la obtención de utilidades; tal es el caso de Banco Compartamos (Bateman, 2010). Incluso cuando se hayan definido los elementos clave en cuanto al mercado, a la organización y al monitoreo de las actividades (Ledgerwood, 1999; Robinson, 2001; Allen, 2007), el proceso para encontrar las mejores prácticas está todavía en marcha. De esta forma, las microfinanzas podrían convertirse en una alternativa viable para el otorgamiento de recursos a los segmentos más pobres de la población debido a los apoyos que reciben por varias instituciones a nivel internacional (Johnson y Rogaly, 1997). No obstante, debido a que uno de los objetivos de las instituciones microfinancieras es la auto-sustentabilidad, es preciso que éstas ofrezcan servicios de ahorro y crédito acordes a las necesidades del mercado meta (Ledgerwood, 1999). En la práctica, estas instituciones enfatizan mucho más el crédito que el ahorro, situación que limita su alcance y desvirtúa su misión ya que compromete su sustentabilidad (Allen, 2007) excluyendo a los más pobres (Robinson, 2001; Hulme, 2007).

\section{Instituciones financieras rurales}

La falta de acceso a los mercados financieros formales conjugada con la necesidad de ahorro y crédito en las zonas rurales impulsa el uso de alternativas que pertenecen al sector financiero informal. En este sector se encuentran aquellos intermediarios no regulados que proveen estos servicios de forma individual o colectiva, tales como: prestamistas, terratenientes, familiares y amigos, asociaciones rotativas de crédito y ahorro, bancos comunales y cajas de ahorro, entre otros (Agénor, et al., 1993; Mansell-Carstens, 1995; Conning y Udry, 2005).

A pesar de las reformas orientadas hacia el fomento de la intermediación financiera formal, las fuentes informales siguen siendo utilizadas en las zonas urbanas y rurales (Alpízar et al., 2006b). La razón por la 
cual coexistirían ambos sectores se fundamenta en el problema de información asimétrica según el cual, los agentes racionados buscarían recursos alternativos en el sector informal (Stiglitz y Weiss, 1981; Hoff y Stiglitz, 1990; Aryeetey y Udry, 1994; Floro y Ray, 1997). Debido a que los hogares obtienen fondos de ambas fuentes, es posible entrever algún grado de complementariedad entre los sectores (Schrader, 1996). No obstante, Diagne (1999) argumenta que éstos son sustitutos imperfectos debido a que en las zonas rurales el crédito informal es generalmente utilizado para financiar el consumo mientras que la contraparte formal financia la producción.

La rigidez de los productos ofrecidos por parte del sector financiero formal en las zonas rurales obstaculiza su uso al no tomar en cuenta la estructura de los flujos de ingresos de los hogares de estas zonas. Consecuentemente, esta situación beneficia al sector informal por haber implementado esquemas de préstamos que se adaptan a las posibilidades de pago de las familias (Lamberte, 1988; Zeller, 1994; Bali-Swain, 2002), de tal manera que la demanda de créditos informales parece ser una consecuencia más no una causa del subdesarrollo de los mercados crediticios (Casolaro, et al., 2006).

\subsection{Características de los sectores financieros}

Las principales características de un préstamo consisten en el monto, el plazo, la tasa de interés y las garantías que avalan el cumplimiento del pago de la deuda.

En términos de montos, los préstamos proporcionados por el sector financiero formal son mayores respecto a los que otorga la contraparte informal. En cuanto al plazo, el sector formal maneja mayores plazos, pero el informal provee los recursos en un lapso mucho más corto debido a que los obstáculos y trámites burocráticos son menores. La rapidez con la cual el deudor obtiene los recursos es particularmente apreciada, sobre todo cuando los fondos están destinados a financiar alguna emergencia. Sin embargo, las tasas de interés que se manejan en el sector informal superan en gran medida las que cobra el sector formal (Agénor et al., 1993).

Las garantías aceptadas por parte del sector financiero formal consisten generalmente en bienes inmuebles (IDB, 2004); por lo anterior, la falta de un colateral, sobre todo por parte de los segmentos más pobres, impide el acceso a este sector (Okurut et al., 2004). No obstante, el sector informal acepta una amplia variedad de colaterales (Raccanello, 2008) y, en algunos casos, la reputación del deudor en la comunidad (colateral social) sustituye el colateral físico (Van Bastelaer, 2000; Dercon y de Weerdt, 2006). En caso de incumplimiento por parte del deudor, ambos sectores 
se apropian de la garantía, limitando los préstamos futuros; sin embargo, mientras que el sector formal actúa según el marco institucional, el informal puede aplicar sanciones considerablemente más severas (Dalla-Pellegrina, 2008).

\subsection{Capital social}

En México, además de las dificultades de acceso a los servicios financieros formales, otro problema relevante consiste en la baja oferta de servicios financieros sustentables y eficientes. Por un lado, en las zonas rurales se observa todavía una importante presencia de subsidios y programas gubernamentales que además de poder presentar una mayor eficiencia podrían desincentivar la introducción de innovaciones; por otro, aún cuando estos problemas se asemejen a las fallas del viejo paradigma de las finanzas rurales, pueden ser resueltos a través de intermediarios financieros que puedan diversificar los riesgos y apoyar las demandas de los hogares y productores agrícolas (González-Vega, 2004).

El nuevo paradigma enfatiza los mecanismos de mercado en los cuales la sociedad civil tiene un rol activo (Durston, 2002; Bouquet, 2007). La carencia de servicios financieros formales ha impulsado a los hogares y a los productores en las zonas rurales a la autorganización fomentada por la presencia del capital social colectivo o comunitario, mismo que consiste en "las estructuras e instituciones sociales de cooperación del conjunto total de personas de una localidad" (Durston, 2002: 30). Desde esta perspectiva, estas organizaciones proporcionarían un servicio que de otra forma los individuos no obtendrían (Lieberman, 1979), permitiendo aminorar las situaciones de pobreza (Woolcock, 1998). Es decir, las organizaciones comunitarias constituirían una forma de subsanar la demanda insatisfecha de bienes públicos y otros servicios (entre los cuales están el ahorro y el crédito), permitiendo mejorar el nivel de vida de sus miembros (Karmakar, 1999; De Janvry y Sadoulet, 2000). Estas organizaciones enfrentan los típicos problemas de acción colectiva, haciendo necesaria la implementación de mecanismos para poder manejar correctamente los incentivos, monitorear a los miembros y aplicar eventuales sanciones (Johnson y Rogaly, 1997; De Janvry y Sadoulet, 2000).

\subsection{Instituciones de aborro y crédito informales}

La presencia de capital social permite que puedan surgir de forma espontánea distintos tipos de organizaciones/asociaciones que se agrupan bajo el concepto de finanzas populares. La flexibilidad que presentan estos esquemas, ligada a su capacidad de adaptación de acuerdo a las posibili- 
dades y necesidades de sus miembros, se resuelve en una amplia variedad de asociaciones (Aryeetey, 1995). Una revisión exhaustiva de estas características rebasa el objetivo de este estudio y ha sido proporcionada por parte de otros autores (Ghate, 1992; Bouman y Hospes, 1994; Robinson, 2001). No obstante, para el propósito de esta investigación, se indican algunos rasgos estilizados de los prestamistas, de las tandas -incluyendo los préstamos de familiares/amigos- y de los grupos solidarios/cajas de ahorro informales.

\subsubsection{Prestamistas}

Posiblemente, la figura que se asocia más con una fuente de recursos de rápido acceso en un entorno rural es la del prestamista. La naturaleza informal, y en varios casos ilegal, de las actividades desempeñadas por estos intermediarios hace particularmente difícil la obtención de información detallada. Pese a lo anterior, algunos rasgos característicos de su actividad consisten en el otorgamiento de créditos, cuyo monto es variable, por plazos relativamente cortos (3-6 meses), avalados por una garantía hipotecaria sobre vehículos, bienes raíces y en menor medida pagarés. Las tasas de interés pueden variar entre 5 y $20 \%$ mensual y de forma inversa al monto prestado.

Los clientes, a pesar del elevado costo del crédito, no perciben al prestamista de forma negativa (Raccanello, 2008). Esta situación, que según Dichter (2007) debería interpretarse tomando en cuenta que la relación entre los proveedores y receptores de los recursos, puede influir sobre la conducta de los deudores.

\subsubsection{Tandas y préstamos de familiares/amigos}

Las asociaciones de ahorro y crédito rotativo conocidas en México con el nombre de tandas o cundinas según la región, son un mecanismo de ahorro que se ha observado en varios países (Geertz 1962; Ardener, 1964). La tanda es constituida por un grupo de entre 10 y 20 individuos que a intervalos regulares aportan una determinada cantidad de dinero. En cada ronda, el total de lo recaudado es asignado a uno de los miembros de acuerdo a un orden preestablecido-aleatorio, por subasta o según alguna regla discrecional (Besley et al., 1993; Kovsted y Lyk-Jensen, 1999).

Los individuos que participan en las tandas pueden ser familiares, amigos o compañeros de trabajo; rara vez participa un individuo que no tenga relación con algunos de los otros miembros. Las mujeres tienden a constituir la mayor parte de los integrantes debido al grado de confianza que suele darse entre ellas (Raccanello et al., 2009). La adhesión a las 
tandas tiene como fin principal el de ahorrar pero también sirven para cultivar relaciones interpersonales debido a la homogeneidad que suele existir entre sus miembros (Vélez-Ibáñez, 1983; 2010).

Los lazos familiares o de estrecha amistad permiten el acceso a recursos en caso de necesidad (Lomnitz, 1975). A diferencia de las tandas, donde el ahorro es un requisito para poder tener acceso al crédito, los préstamos por parte de familiares o amigos son otorgados considerando cierta reciprocidad (Morduch, 1999). También, la ayuda proporcionada puede extenderse a otros conceptos, tales como comida, ropa y trabajo (Stoller y Pugliesi, 1991; Fafchamps y Lund, 2003). En particular, proporcionar ayuda implica la existencia de confianza entre las partes ya que aumenta la vulnerabilidad de quien la ofrece (Lorenz, 1991); no obstante, recibir la ayuda implica adquirir de forma implícita la obligación moral de tener que apoyar a quien la haya otorgado en caso de necesidad. Las relaciones de reciprocidad ocurren y presentan mayor estabilidad entre individuos y hogares de nivel socio-económico similar (Fafchamps, 1992).

\subsubsection{Cajas de ahorro informales}

A diferencia de las tandas, cada miembro de una caja de ahorro informal (CAI) puede ahorrar una distinta cantidad de dinero y, de acuerdo a lo establecido en la CAI, puede recibir préstamos sujetos al pago de una tasa de interés preferencial. La estructura organizativa que mejor describe a las cajas de ahorro informales es la de un grupo solidario (self-help group), pero el número de miembros en las CAI es generalmente mayor, por lo cual los préstamos monetarios son también mayores.

En México, a pesar de la proliferación de las CAI, la investigación es escasa. ${ }^{1}$ No obstante, los estudios más relevantes de corte cualitativo que han analizado estas asociaciones constituyen una valiosa fuente de información. Desde esta perspectiva, Zapata Martelo et al. (2003) documentan la presencia de las cajas de ahorro informales en México, a veces constituidas como asociaciones civiles, ofreciendo un testimonio de los beneficios y costos que sus miembros perciben a nivel económico y social. A pesar de las desventajas económicas que enfrenta la población rural, los individuos están dispuestos a ahorrar en términos monetarios, o en especie (Fiebig et al., 1999; Conde-Bonfil, 2001; Campos-Bolaño, 2005). La evidencia demuestra que las CAI constituyen un medio que logra el empoderamiento de las mujeres en un entorno rural (Zapata-Martelo et al., 2003).

\footnotetext{
${ }^{1}$ Para un reciente y actualizado panorama de las instituciones microfinancieras formales en México véase Rodríguez-Vázquez (2010).
} 
Debido a la naturaleza informal de los grupos solidarios y de las CAI, y considerando que las funciones de ambas estructuras coinciden, los grupos solidarios pueden ser considerados como sinónimo de las CAI. La literatura en torno a los grupos solidarios para el caso de la India es particularmente informativa sobre la forma de operar y de su alcance (Karmakar, 1999). El aspecto más relevante de los grupos solidarios consiste en que proporcionan servicios informales de ahorro y crédito, promoviendo el empoderamiento de las mujeres que constituyen la mayoría de sus miembros. Asimismo, otra ventaja de participar en estos grupos consiste en recurrir con menor frecuencia a los prestamistas y una menor sumisión de los deudores a las voluntades de los acreedores (Padia, 2005; Rajivan, 2005; International Labour Organization, 2006).

\subsubsection{Funcionamiento de las CaI en el municipio} de Santo Tomás Hueyotlipan

El municipio de Santo Tomás Hueyotlipan se ubica en la zona central del estado de Puebla y está conformado por la cabecera municipal homónima y la junta auxiliar de San Miguel Zacaola. En la cabecera municipal de Santo Tomás Hueyotlipan, donde se tiene conocimiento de la existencia de al menos dos CAI, en el 2007 se aplicó un cuestionario ${ }^{2}$ a 250 personas para conocer distintos aspectos de estas organizaciones.

Las cajas de ahorro que operan en la cabecera municipal son informales al no estar registradas ni supervisadas por ninguna instancia gubernamental o financiera. En particular, los miembros acuerdan desde el comienzo de la organización de la CaI la cantidad que cada uno de ellos se compromete a ahorrar semanalmente.

La participación en las CAI es voluntaria, pero está sujeta a que uno de los miembros, ya afiliados o que cuente con un historial de participación, invite a el o a los nuevos integrantes. Si bien no hay responsabilidad pecuniaria por parte de quién introduce un nuevo miembro a la organización existe una responsabilidad moral implícita si el nuevo miembro no cumple con sus obligaciones.

Los miembros asisten una vez por semana a las reuniones de la CAI y entregan el ahorro al tesorero; en caso de incumplimiento, la falta es sancionada con una multa de 50 pesos semanales. El tesorero, cuyo cargo dura un ańo, es quien se encarga de resguardar el dinero, y es generalmente elegido por turno $(57.14 \%)$, por mayoría $(22.08 \%)$ o por consenso $(18.18 \%)$ por parte de los miembros. Hay una estrecha relación entre

\footnotetext{
${ }^{2}$ La metodología utilizada para el muestreo se indica en la siguiente sección.
} 
los miembros de las CAI; ninguno de ellos reportó alguna falta de confianza, de hecho, $90 \%$ son amigos o vecinos y el restante $10 \%$ son familiares.

En general la CAI presta todo lo recaudado (ahorros y multas) de acuerdo a un orden preestablecido y por una sola vez al año; para los miembros de la CAI los préstamos generan una tasa de interés pasiva entre el 2 y $3 \%$ mensual. En caso de quedar algún excedente, éste puede ser prestado tanto a miembros como a no miembros. Estos últimos pueden recibir un préstamo sujeto a que uno de los miembros funja como aval y a una mayor tasa de interés (entre 5 y $7 \%$ mensual). En otras cajas se presta sólo una parte de lo recaudado y lo restante se mantiene en el fondo para financiar alguna necesidad imprevista de los miembros.

Aun cuando las CAI tengan algunos rasgos parecidos a los de las tandas, hay también algunas diferencias: 1 . Los préstamos de las CAI se limitan a uno por año por cada miembro, mientras que en las tandas es posible recibir los ahorros acumulados de acuerdo al número de turnos que posee un individuo. Asimismo, las CAI pueden prestar recursos a personas que no son miembros de las mismas, situación que no ocurre en las tandas. 2. El número de miembros de las CAI es mayor al de las tandas, por lo cual éstas logran tener a disposición una mayor cantidad de recursos y los préstamos monetarios pueden rebasar los montos que pondría a su disposición una tanda. 3. Los préstamos de las CAI están sujetos al pago de una tasa de interés, mientras que en las tandas generalmente no hay ningún costo por el uso de los recursos ${ }^{3}$. 4. La obtención de los préstamos en las CAI es voluntaria mientras que en las tandas éste se obtiene según el orden preestablecido al comienzo de la asociación. 5. En las CAI, debido al pago de los intereses sobre los préstamos otorgados y las multas, los miembros, adicionalmente a los ahorros acumulados durante el año, reciben parte proporcional de este monto, lo que les permite compensar la pérdida de poder adquisitivo debido a la inflación, situación que en las tandas generalmente no ocurre. Una parte importante de estas ganancias son destinadas a financiar los convivios entre familiares y amigos, mismos que, a su vez, fomentan los lazos afectivos. De este modo, la presencia de nuevas formas de intermediación, como las CAI, puede alterar el uso de los mecanismos tradicionales de financiamiento (tandas, préstamos de familiares/amigos y prestamistas) debido a sus características.

\footnotetext{
${ }^{3}$ La literatura especializada sobre este tema enfatiza la flexibilidad de estos instrumentos; un interesante y actualizado análisis de la heterogeneidad en cuanto a las distintas características de las tandas/cundinas se resume en Vélez-Ibáñez (2010).
} 


\section{Objetivo del estudio, hipótesis y metodología}

Debido a la escasez de información sobre las CAI en México, en este estudio se analizan las determinantes de la participación en las cajas de ahorro informales; la hipótesis de este trabajo considera que las CAI atraen a aquellos individuos que utilizan otros métodos tradicionales de financiamiento (tandas, préstamos de familiares/amigos y prestamistas). Es decir, que los individuos ven a estas organizaciones como un medio alternativo para la obtención de créditos.

Como se ha mencionado en la sección anterior, el estudio se llevó a cabo en la cabecera municipal de Santo Tomás Hueyotlipan. El municipio presenta un índice de marginación medio pero, el desarrollo urbano y la disponibilidad de servicios en la cabecera municipal son sensiblemente mayores a los de la junta auxiliar; por esta razón, las actividades rurales se concentran en esta última. A nivel municipal ${ }^{4}$, el sector primario abarca $53.9 \%$ de las actividades que se desempeñan y ocupa $44.25 \%$ de la población económicamente activa (Sagarpa y Secretaría de Desarrollo Rural del Estado de Puebla, 2006). Además de ser una localidad rural, ésta fue elegida por no contar con ningún intermediario financiero formal, pero sí con la presencia de al menos dos CAI. La necesidad de recursos por parte de los habitantes de Santo Tomás Hueyotlipan es evidente, el diagnóstico elaborado por la Sagarpa y la Secretaría de Desarrollo Rural del Estado de Puebla (2006) menciona de forma explícita esta necesidad en varias ocasiones.

Después del piloteo del instrumento en la misma localidad, durante los meses de agosto y septiembre de 2007, a través de un muestreo aleatorio sistemático, se seleccionaron 250 hogares en la cabecera municipal en los cuales sería aplicado el cuestionario. Debido a que la zona urbana de la cabecera municipal está conformada por aproximadamente 12 cuadras de norte a sur y de este a oeste, se completó el tamaño requerido con relativa facilidad, seleccionando en promedio dos hogares de forma aleatoria en cada cuadra. Una vez determinados los hogares, el proceso para el levantamiento de la información consistió en visitar personalmente a cada uno de ellos. Las visitas se realizaron entre las 11 de la mañana y la una de la tarde y de las tres y hasta las seis de la tarde de lunes a domingo en los hogares del centro y de las zonas periféricas de la cabecera municipal.

Previa identificación de uno de los autores, se preguntó a un adulto, de preferencia el padre o la madre, si estaba dispuesto a contestar el

\footnotetext{
${ }^{4}$ La Sagarpa y la Secretaría de Desarrollo Rural del Estado de Puebla (2006) no proporcionan datos desglosados para la cabecera municipal y la junta auxiliar.
} 
cuestionario, ${ }^{5}$ garantizando el anonimato de la información proporcionada. En aproximadamente 38\% de los casos fue necesario realizar más de una visita debido a que no se lograba ubicar a los residentes (no había nadie en el hogar o se encontraban personas en edad avanzada, o menores de edad); si bien esta situación incrementó el tiempo necesario para poder levantar la información se logró mantener una relativamente baja tasa de no respuesta (aproximadamente 23\%). Los hogares en los cuales no fue posible aplicar el cuestionario (sea porque después de tres visitas no se logró ubicar a ningún integrante mayor de 18 años o frente a la negativa de querer contestar el instrumento) fueron reemplazados por otros, hasta alcanzar el tamaño muestral requerido. Sobre indicación de un familiar, algunos cuestionarios fueron también aplicados a personas que no se encontraban en sus domicilios sino en su lugar de trabajo o en el vecindario.

El instrumento estaba integrado por 50 preguntas cerradas de opción múltiple, por lo cual los aspectos cualitativos relacionados con las características de las CAI y de otras fuentes de recursos pudieron ser captados únicamente de forma somera pero consistente. De esta manera se obtuvo información relacionada con las características socioeconómicas de los encuestados y de sus hogares (composición, ingresos, ahorros, sectores de actividad), el acceso y el uso de mecanismos financieros informales (cajas de ahorro informales, tandas, familiares/amigos y prestamistas).

\subsection{Resultados de la encuesta}

\subsubsection{Características socioeconómicas}

De las 250 personas entrevistadas en la cabecera del municipio ${ }^{6}, 51.2 \%$ desempeńa actividades no agrícolas -tratándose principalmente de comercio al menudeo, administrando un negocio propio o siendo empleado por terceros- en las cuales se involucran principalmente las mujeres (69.53\%). Por otro lado, 32.8\% combina actividades agrícolas y no agrícolas (las mujeres participan en ellas con $91.46 \%$ ), y el restante $16 \%$ se dedica exclusivamente a las actividades agrícolas donde predomina el trabajo masculino (72.5\%). Los que se desempeñan en el campo tienden a trabajar sus propios terrenos (45\%), cuya extensión no rebasa las dos hectáreas en $83.3 \%$ de los casos.

\footnotetext{
${ }^{5}$ Para una población de 5,000 personas, una muestra de 250 observaciones permite alcanzar una significancia de $95 \%$, con un intervalo de confianza de $6 \%$.

${ }^{6}$ Las diferencias entre los resultados de la encuesta y la información reportada por la Sagarpa y la Secretaría de Desarrollo Rural del Estado de Puebla (2006), en relación a la participación en los sectores de actividad económica, se deben a que el cuestionario fue aplicado únicamente en la cabecera municipal donde, debido a un mayor desarrollo urbano respecto al de la junta auxiliar, las actividades agrícolas no constituyen la principal fuente de ocupación.
} 
Más de $80 \%$ de la muestra tiene educación básica (primaria y secundaria: 55.2 y $30 \%$ respectivamente) y los niveles de ingreso mensuales de los hogares son bajos: $42.4 \%$ no rebasa los 1,200 pesos y $45.6 \%$ se ubica entre 1,201 y 2,400 pesos. En línea con lo anterior, 60\% de los entrevistados no tiene ahorros (Cuadro 1).

Cuadro 1

\section{Niveles de ahorro}

\begin{tabular}{lrrrrrr}
\hline & \multicolumn{2}{c}{ No pertenece a las CAI } & \multicolumn{2}{c}{ Pertenece a las CAI } & \multicolumn{2}{c}{ Muestra total } \\
\cline { 2 - 7 } \multicolumn{1}{c}{ Ahorros (pesos) } & \multicolumn{1}{c}{ Obs. } & \multicolumn{1}{c}{$\%$} & \multicolumn{1}{c}{ Obs. } & \multicolumn{1}{c}{$\%$} & \multicolumn{1}{c}{ Obs. } & \multicolumn{1}{c}{$\%$} \\
\hline Sin ahorros & 146 & 84.39 & 4 & 5.19 & 150 & 60.00 \\
Hasta 3,000 & 19 & 10.98 & 8 & 10.39 & 27 & 10.80 \\
De 3,001 a 5,000 & 6 & 3.47 & 27 & 35.06 & 33 & 13.20 \\
De 5,001 a 10,000 & 2 & 1.16 & 25 & 32.47 & 27 & 10.80 \\
De 10,001 a 20,000 & 0 & 0 & 8 & 10.39 & 8 & 3.20 \\
Más de 20,000 & 0 & 0 & 5 & 6.49 & 5 & 2.00 \\
Totales & 173 & 100 & 77 & 100 & 250 & 100 \\
\hline
\end{tabular}

Nota: La prueba U de Mann-Whitney rechaza la igualdad de las distribuciones del nivel de ahorro según la membresía a las CAI: $Z=-12.793(\mathrm{p}<0.001)$.

Fuente: Elaboración propia con base en los resultados de la encuesta.

El municipio no cuenta con ninguna sucursal bancaria y sólo 8.8\% de la muestra (22 individuos) ha solicitado algún crédito a una institución financiera formal, de ellos sólo cinco lo obtuvo. Las razones para no solicitar un crédito formal radican principalmente en: los trámites burocráticos (31.6\%), en la falta de interés/información en cuanto a los productos financieros que ofrece el sector formal $(31.4 \%)$ y el elevado costo $(23.25 \%)$.

\subsubsection{Participación en las CAI}

Del total de la muestra, 30.8\% (77 individuos) pertenece a una CAI principalmente con el fin de ahorrar y pedir préstamos $(85.71 \%)$ o para poder enfrentar alguna emergencia (14.29\%). Al interior de las CAI, los problemas entre los miembros y el no recibir el préstamo en caso de necesidad parecen ser de importancia secundaria (10.4 y $5.2 \%$ respectivamente). El restante $69.2 \%$ de la muestra no es miembro de una CAI por falta de interés $(35.84 \%)$, porque no ha sido invitada a participar (32.95\%), o por falta de tiempo (13.29\%).

A pesar de que la distribución de los ingresos de los hogares no muestra diferencias de acuerdo a la participación en la CAI, posiblemente por 
la homogeneidad socioeconómica de la localidad, los datos son contundentes en afirmar que los participantes presentan mayores niveles de ahorro (Cuadro 1).

Treinta y cinco punto seis por ciento de los participantes ahorra semanalmente una cantidad que varía entre 101 y 200 pesos, mientras que los préstamos son utilizados para cubrir necesidades de consumo y de inversión; en particular, gastos educativos (29.87\%), mantenimiento de la casa (24.68\%), inversión en parcela/negocio $(23.38 \%)$ y gastos médicos (16.88\%).

Pertenecer a una CAI parece ser una alternativa al uso de otros métodos de financiamiento, ya que sólo $16.88 \%$ de los miembros recurre a tandas, préstamos de familiares/amigos o a algún prestamista.

\subsection{Descripción de las variables y de los modelos}

La metodología para la comprobación de la hipótesis prevé la estimación de un modelo probit con errores estándares robustos (Huber-White) debido a la presencia de heteroscedasticidad. En el modelo, la variable dependiente miembro_CAI toma valor de 1 si el individuo es miembro de la CAI, 0 en caso contrario. El modelo probit permite estimar el cambio en la probabilidad de que la variable dependiente cambie de 0 a 1 asocia$\mathrm{da}$ a una variación en una variable independiente. El software Stata permite obtener la magnitud del cambio marginal en la probabilidad a través del comando dprobit evitando así la transformación de los coeficientes estimados en probabilidades.

Las variables independientes del modelo se indican a continuación; éstas abarcan características individuales y del hogar relacionadas con la esfera socioeconómica. Asimismo, se incorporan variables que representan el uso de distintos sistemas de financiamiento.

El género del individuo es representado por la variable dicotómica mujer que toma valor de 1 si el encuestado es una mujer, 0 si es hombre. El estado civil está representado por las variables dicotómicas pareja que toma valor de 1 si el encuestado está casado o vive en unión libre y soltero que toma valor de 1 si el encuestado es soltero, 0 en caso contrario. Hijos es una variable discreta que indica el número de hijos que viven en el hogar. ${ }^{7}$

La edad del encuestado está representada por la variable edad y el nivel de escolaridad se incorpora al modelo a través de las variables dicotómicas primariaomenos y secundaria que toman valor de 1 si el encuestado tiene estudios hasta el nivel de primaria o de secundaria, 0 en caso

\footnotetext{
${ }^{7}$ La variable incluye cualquier hijo(a) que viva en el hogar sin importar su edad.
} 
de no contar con estudios. La categoría de referencia, omitida en el modelo, representa un nivel de estudio igual o superior al de preparatoria. Debido a que en el municipio de Santo Tomás Hueyotlipan se ha detectado un flujo migratorio por falta de trabajo, la variable dicotómica migrantes toma valor de 1 si algún miembro del hogar ha migrado a los Estados Unidos, 0 en caso contrario.

Asimismo, debido a que $32 \%$ de los encuestados está inscrito en al menos un programa de gobierno, en este caso la variable dicotómica programa_gob toma valor de 1, 0 en caso contrario. Algunos de estos programas (Procampo y Oportunidades), proporcionan ayuda económica a los hogares; las variables procampo-monto y oportunidades-monto, indican la cantidad monetaria que recibe anualmente el hogar.

Como proxy de los activos de los cuales dispone el hogar, la variable dicotómica terrenos-propios toma valor de 1 si el hogar al cual pertenece el encuestado dispone de tierra propia; maiz y frijol son variables dicotómicas que toman valor de 1 si el hogar cultiva estos productos que son los más comunes en la localidad, 0 en caso contrario. Para tomar en cuenta el desarrollo de actividades no agrícolas, en este caso la variables actividad-no-agricola toma valor de 1, 0 en caso contrario.

El ingreso mensual del hogar se incluyó en el modelo a través de cuatro variables dicotómicas; para ello se determinaron las variables ingfam-1200, ing-fam-1201-2400 e ing-fam-2401-4800 que toman valor de 1 si el ingreso mensual es inferior o igual a 1,200 pesos, entre 1,201 y 2,400 pesos o entre 2,401 y 4,800 pesos, 0 en caso contrario. La categoría de referencia consiste en aquellos hogares que perciben más de 4,800 pesos mensuales. De forma similar se definieron las variables que indican los ahorros totales del hogar: no-ahorro (el hogar no dispone de ningún ahorro), ahorro-3000 (ahorros totales entre 1 y 3,000 pesos), ahorro-3001-5000 (ahorros totales entre 3,001 y 5,000 pesos). La categoría de referencia, omitida en el modelo corresponde a los hogares que poseen más de 5,000 pesos ahorrados.

Finalmente, para tomar en cuenta el uso de otros sistemas de financiamiento, se añadieron al modelo las variables tanda, prestamista y préstamo-familia que toman valor de 1 si el individuo ha ahorrado en tandas, o recibido algún crédito por un prestamista o familiar/amigo respectivamente, 0 en caso contrario. Las variables continuas tandamonto, prestamista-monto y préstamo-familia-monto representan las cantidades monetarias recibidas por las tandas, prestamistas y por los familiares/amigos, respectivamente. En relación al acceso al préstamo formal, la variable solicitud-cred-formal toma valor de 1 si el individuo ha solicitado algún crédito formal, 0 en caso contrario. Ninguno de los encuestados a los cuales fue otorgado el crédito formal participa en una CAI, por lo cual 
no se incluyeron los préstamos otorgados por este sector en el modelo. No obstante, al haberse detectado algunos casos de autoexclusión de los mercados financieros formales (personas que no solicitaron el crédito porque creían que no lo iban a recibir), se incorporó al modelo la variable autoexclusión-mff que para estos casos toma valor de 1 y 0 en caso contrario. Otras causas para no solicitar algún crédito son incorporadas al modelo por medio de las variables caro, trámites y no-garantía que toman valor de 1 si el crédito no fue solicitado por su alto costo, por los trámites o por no poseer garantías respectivamente. La falta de interés como razón para no solicitar el crédito no fue incluida en el modelo para evitar un problema de multicolinealidad.

Aun cuando hubiera podido existir un problema de endogeneidad entre la participación en la CAI y el nivel de ahorro, la prueba de Hausman no proporcionó evidencia en este sentido, por lo que no fue necesario estimar el modelo haciendo uso de variables instrumentales. Los resultados de las estimaciones se reportan en la tabla 1 ; los valores que aparecen en las columnas encabezadas por $\mathrm{dF} / \mathrm{dx}$ indican el cambio marginal en la probabilidad de que el individuo pertenezca a una caja de ahorro informal.

\subsection{Resultados}

No obstante que la literatura reporte que los grupos solidarios suelen estar constituidos principalmente por mujeres, y aún cuando el signo de la variable mujer resulta correcto, en este estudio no hay evidencia de que el género se asocie con la participación en las CAI; debido a que en el municipio de Santo Tomás Hueyotlipan la formación de las CAI no es consecuencia de algún programa gubernamental, sino que su organización puede interpretarse como la respuesta por parte de los miembros a sus necesidades de ahorro y crédito, este resultado deja entrever que estos esquemas no limitan la admisión de acuerdo a criterios basados en el género. Esta situación se contrapone a lo que ocurre en el sector financiero formal, donde tradicionalmente, por los requisitos que solicita, se ha limitado el acceso a las mujeres (Van Staveren, 2002).

El estado civil se relaciona con la participación a una CAI únicamente para las personas solteras, quienes presentan una mayor probabilidad de ser miembro de las CAI (entre 30.4 y $34.1 \%$ ). La presencia de hijos en el hogar se asocia con una mayor participación; en particular, por cada hijo $^{8}$ la probabilidad de participación aumenta entre 5.8 y $6.4 \%$ (por

${ }^{8}$ En una versión alternativa del modelo (estimaciones no reportadas) al incluir el número de hijos en el hogar según el rango de edad (0-5 años, 6-12, 13-18 y mayores de 19 años), se relacionan de forma significativa con una mayor participación sólo aquellos en el rango $0-5$ ańos $(+8.3 \%)$ y $13-18$ ańos $(+12.9 \%$ por cada hijo adicional). Es impor- 
Tabla 1

Estimaciones modelo probit

\begin{tabular}{|c|c|c|c|c|c|c|}
\hline \multirow[b]{2}{*}{ Miembro de una $C A I=1$} & \multicolumn{3}{|c|}{ Modelo núm.1 } & \multicolumn{3}{|c|}{ Modelo núm. 2} \\
\hline & $d F / d x$ & $\begin{array}{l}\text { Err. est. } \\
\text { Robustos }\end{array}$ & & $d F / d x$ & $\begin{array}{l}\text { Err. est. } \\
\text { Robustos }\end{array}$ & \\
\hline Mujer & 0.110 & 0.061 & & 0.057 & 0.067 & \\
\hline Pareja & 0.080 & 0.096 & & 0.075 & 0.100 & \\
\hline Soltero & 0.341 & 0.231 & $*$ & 0.304 & 0.224 & $*$ \\
\hline Hijos & 0.064 & 0.030 & $* * *$ & 0.058 & 0.031 & $* *$ \\
\hline Edad & 0.006 & 0.002 & $* * *$ & 0.006 & 0.002 & $* *$ \\
\hline Primariaomenos & -0.136 & 0.129 & & -0.129 & 0.127 & \\
\hline Secundaria & -0.173 & 0.070 & $* *$ & -0.191 & 0.072 & $* *$ \\
\hline Migrantes & 0.352 & 0.201 & $* *$ & 0.320 & 0.191 & $* *$ \\
\hline Programa-gob & 0.065 & 0.081 & & 0.048 & 0.081 & \\
\hline Procampo-monto & $-1.12 \mathrm{E}-05$ & $8.03 \mathrm{E}-05$ & & $3.80 \mathrm{E}-05$ & $9.87 \mathrm{E}-05$ & \\
\hline Oportunidades-monto & $-1.26 \mathrm{E}-04$ & $7.24 \mathrm{E}-05$ & * & $-1.13 \mathrm{E}-04$ & $7.36 \mathrm{E}-05$ & * \\
\hline Terrenos-propios & -0.131 & 0.044 & $* *$ & -0.102 & 0.053 & \\
\hline Maíz & 0.274 & 0.086 & $* * *$ & 0.200 & 0.087 & ** \\
\hline Frijol & 0.056 & 0.106 & & 0.027 & 0.094 & \\
\hline Actividad-no-agrícola & 0.033 & 0.064 & & 0.031 & 0.067 & \\
\hline Ing-fam-1200 & 0.621 & 0.216 & $* * *$ & 0.537 & 0.224 & ** \\
\hline Ing-fam-1201-2400 & 0.498 & 0.230 & $* *$ & 0.428 & 0.232 & ** \\
\hline Ing-fam-2401-4800 & 0.625 & 0.354 & * & 0.489 & 0.378 & \\
\hline No-ahorro & -0.964 & 0.026 & $* * *$ & -0.944 & 0.033 & $* * *$ \\
\hline Ahorro-3000 & -0.194 & 0.056 & $* * *$ & -0.195 & 0.052 & $* * *$ \\
\hline Ahorro-3001-5000 & -0.085 & 0.060 & & -0.096 & 0.063 & \\
\hline Tanda & -0.154 & 0.046 & $* * *$ & & & \\
\hline Prestamista & -0.126 & 0.040 & ** & & & \\
\hline Préstamos-familia & -0.077 & 0.066 & & & & \\
\hline Tanda-monto & & & & $-1.35 \mathrm{E}-05$ & 7.91E-06 & $*$ \\
\hline Prestamista-monto & & & & $-5.16 \mathrm{E}-05$ & $1.73 \mathrm{E}-05$ & $* * *$ \\
\hline Préstamos-familia-monto & & & & $-2.83 \mathrm{E}-05$ & $1.30 \mathrm{E}-05$ & ** \\
\hline Solicitud-cred-formal & -0.048 & 0.080 & & -0.073 & 0.072 & \\
\hline Autoexclusión-mff & -0.071 & 0.059 & & -0.078 & 0.056 & \\
\hline Caro & -0.012 & 0.077 & & -0.023 & 0.074 & \\
\hline Trámites & 0.078 & 0.094 & & 0.061 & 0.093 & \\
\hline No-garantía & 0.061 & 0.156 & & 0.013 & 0.140 & \\
\hline & Wald ch & $\mathrm{i} 2(29)=126$. & $30^{* * *}$ & Wald chi & $2(29)=181$. & $68^{* * *}$ \\
\hline${ }^{*} \mathrm{p}<0.1$; $^{* *} \mathrm{p}<0$. & $\begin{array}{l}\quad \mathrm{P} \\
\log \mathrm{ps} \\
0.01\end{array}$ & $\begin{array}{l}\text { seudo } R 2=0 \\
\text { eudo-likelih }\end{array}$ & $\begin{array}{l}7294 \\
\text { ood }= \\
41.77\end{array}$ & $\begin{array}{r}\text { Ps } \\
\text { Log pse }\end{array}$ & $\begin{array}{l}\text { seudo } R 2=0 \text {. } \\
\text { eudo-likelih }\end{array}$ & $\begin{array}{l}7176 \\
\text { ood }= \\
43.59\end{array}$ \\
\hline
\end{tabular}

Fuente: Estimaciones de los autores a partir de las encuestas realizadas. 
ejemplo, con dos hijos en el hogar en términos marginales, ceteris paribus, la probabilidad de pertenecer a una CAI aumentaría entre 11.6 y $12.8 \%$ ). Con base en este resultado, aquellas familias con un elevado número de hijos estarían particularmente propensas a participar, posiblemente porque un mayor número de hijos estimula el interés en ahorrar para hacer frente a sus posteriores necesidades, y también en solicitar algún crédito para enfrentar imprevistos. Además de los motivos precautorios, la entrada de los hijos al mercado laboral puede fomentar la decisión de pertenecer a una caja de ahorro con el fin de tener acceso a los servicios de depósito frente a la falta de intermediarios financieros formales.

De forma similar, en la medida en la que el individuo tiene una mayor edad, aumenta la probabilidad de participación $(+0.6 \%$ por cada año cumplido); esto podría deberse a que una mayor edad se asocia con una mayor madurez que, al ser reconocida por parte de los miembros de la CAI, podría facilitar el acceso a la asociación. Debido a que la participación en la CAI está sujeta a la capacidad de ahorro, se podría esperar un comportamiento no lineal entre la probabilidad de participación y la edad de acuerdo a un patrón de "U” invertida según la hipótesis del ciclo de vida. Esta hipótesis plantea que los individuos tienden a endeudarse cuando son jóvenes; situación que se revierte conforme la edad aumenta, por lo cual las personas comienzan a ahorrar durante su vida productiva para cuando se jubilan. Es en esta última etapa que los individuos al dejar de trabajar reducen sus ahorros en términos netos. Esto dejaría entrever que, ceteris paribus, al incrementar la edad la probabilidad de participación aumentaría para sucesivamente reducirse; no obstante, debido a que en el modelo se incluyen las variables correspondientes a los niveles de ahorro, se detectó sólo la presencia de un comportamiento lineal estadísticamente significativo.

El diagnóstico municipal del 2006 (Sagarpa y Secretaría de Desarrollo Rural del Estado de Puebla, 2006) y los resultados de la encuesta, coinciden en señalar que el nivel escolar promedio en Santo Tomás Hueyotlipan es bajo (Cuadro 2). En línea con estos resultados, el contar con un nivel educativo de secundaria, respecto al nivel de preparatoria o mayor, reduce la probabilidad de participar en una CAI (entre -19.1 y $-17.3 \%$ ). A mayores niveles de estudios los individuos pueden ser más conscientes de la importancia de mantener un ahorro y cierta disciplina financiera en el hogar que, en la medida de lo posible, les permita hacer frente a algún imprevisto o necesidad.

tante considerar que las estimaciones asumen linealidad entre cambios en la variable independiente y variaciones en la probabilidad de que la independiente cambie de 0 a 1 . 
Cuadro 2

Niveles de educación

\begin{tabular}{lrrrrrr}
\hline & \multicolumn{2}{c}{ No pertenece } & las CAI & \multicolumn{2}{c}{ Pertenece a las CAI } & \multicolumn{2}{c}{ Muestra total } \\
\hline \multicolumn{1}{c}{ Escolaridad } & Obs. & \multicolumn{1}{c}{$\%$} & Obs. & $\%$ & \multicolumn{1}{c}{ Obs. } & \multicolumn{1}{c}{$\%$} \\
\hline Ninguna & 7 & 4.05 & 1 & 1.30 & 8 & 3.20 \\
Primaria & 97 & 56.07 & 41 & 53.25 & 138 & 55.20 \\
Secundaria & 51 & 29.48 & 24 & 31.17 & 75 & 30.00 \\
Preparatoria & 13 & 7.51 & 7 & 9.09 & 20 & 8.00 \\
Licenciatura & 5 & 2.89 & 3 & 3.90 & 8 & 3.20 \\
Posgrado & 0 & 0 & 1 & 1.30 & 1 & 0.40 \\
Totales & 173 & 100 & 77 & 100 & 250 & 100 \\
\hline
\end{tabular}

Nota: La prueba U de Mann-Whitney no rechaza la igualdad de las distribuciones del nivel de escolaridad según la membresía a las CAI: $\mathrm{Z}=-1.144$ ( $\mathrm{p}=0.2527$ ).

Fuente: Elaboración propia con base en los resultados de la encuesta.

El mismo diagnóstico revela que la migración es un aspecto que impacta negativamente a la localidad; cuando en el hogar del encuestado algún miembro migró (de los 24 casos detectados todos emigraron a los Estados Unidos y envían remesas) se observa una mayor probabilidad de participación (entre 32 y 35.2\%). Debido a la falta de intermediarios financieros formales en el municipio, ser miembro de una CAI permite poder ahorrar parte de las remesas y tener acceso a los fondos en caso de necesidad, sin tener que acudir a alguna institución financiera formal y enfrentar el tiempo de traslado así como el costo de transporte correspondiente.

A pesar de que la localidad de Santo Tomás Hueyotlipan se especializa en las actividades agrícolas, posiblemente por haber levantado la muestra en la cabecera municipal, o por no recibir fondos de Procampo, ni estar inscrito en algún programa de gobierno, se relaciona con la participación en las CaI. Sólo aquellos hogares que reciben apoyo del programa Oportunidades muestran una menor probabilidad de participar en una CAI (entre -12.6 y $-11.3 \%$ por cada mil pesos de transferencia). Los hogares que perciben el apoyo de Oportunidades son aquellos que, antes de la inscripción al programa, presentaban una situación de elevada vulnerabilidad en términos monetarios, de salud y educación.

Si los individuos consideran las CAI como un mecanismo de aseguramiento (el tener acceso a un crédito permite poder hacer frente a variaciones en el ingreso o en el gasto del hogar en caso de alguna contingencia) entonces, debido a los servicios de educación, salud e ingreso que proporciona el programa, la menor probabilidad de participación se podría 
asociar con un desplazamiento de las cajas informales, una situación ya observada en otros países con las redes de ayuda mutua y otros intermediarios. ${ }^{9}$ Por lo contrario, si las CAI se consideran como un mecanismo de ahorro, debido a que la vulnerabilidad del hogar puede ser aminorada por parte de los beneficios del programa, éstos estarían mostrando una menor propensión a participar en una CAI debido a las transferencias que representan un mayor ingreso para el hogar.

Desde un punto de vista de las actividades que desempeña la unidad familiar, sólo el cultivo del maíz, pero no el del frijol, se asocia con una mayor participación (entre 20 y 27.4\%); el desempeñar actividades ajenas al campo no tiene ninguna relevancia en la participación en la CAI debido a que la probabilidad asociada además de pequeña no es significativa. Este resultado indica que el sector laboral en el cual se desempeña el individuo no se asocia con ser miembro de la CAI. De acuerdo a este resultado las CAI son incluyentes; es decir, tanto los trabajadores rurales, como los que desempeñan otras actividades (por ejemplo el comercio al menudeo), pueden aprovechar los servicios y beneficios que les permite alcanzar ser miembros de la asociación.

Las estimaciones revelan que bajos niveles de ingresos mensuales (hasta 2,400 pesos) se asocian con una mayor participación. No obstante, cuando los ahorros acumulados son bajos (inferiores a 3,000 pesos) la probabilidad de participación es menor. Por un lado, estos resultados indican que los individuos que residen en hogares con menos recursos pueden mostrar un mayor interés en participar en las CAI porque éstas pueden ser utilizadas como un instrumento de aseguramiento para amortiguar las consecuencias monetarias que se derivan de eventuales riesgos que, según la severidad, podrían tener un efecto desestabilizador en las finanzas del hogar (World Bank, 2001). Por otro lado, es relevante mencionar que si el hogar carece de ahorros (no-ahorro), ceteris paribus, es muy difícil que éste pueda participar (la probabilidad se ubica entre -96.4 y $-93.7 \%$ ), mientras que en la medida en la cual el ahorro sea de hasta 3,000 pesos (ahorro-3000), la probabilidad de participar, aún siendo negativa, aumenta sensiblemente. Este resultado, apoyado en la prueba de Hausman que detectó ausencia de endogeneidad entre la participación en la CAI y el nivel de ahorro, indica que la falta de ahorros desincentiva la participación en las CAI. Si se asume que un bajo nivel de ahorro puede indicar una baja capacidad o constancia de ahorro, debido a que participar en las CAI implica asumir el compromiso de ahorrar constantemente un determinado monto, probablemente estos hogares incurrirían

\footnotetext{
${ }^{9}$ Una revisión de estos estudios se encuentra en Clarke y Dercon (2009).
} 
en una sanción monetaria (multas) y otra social (pérdida de reputación entre los miembros de la CAI).

Es relevante señalar que el haber solicitado algún crédito al sector formal, no tiene ninguna relación con la probabilidad de pertenecer a una CAI. De la misma forma, ninguna de las razones que justificaron el no haber solicitado un crédito formal resultó significativa.

En torno a la relación entre ser miembro de una CAI y el uso de los mecanismos tradicionales de financiamiento, en el modelo número uno se aprecia que pertenecer a una tanda (tanda) o haber solicitado un crédito a un prestamista (prestamista) reducen la probabilidad de pertenecer a una CAI, lo cual contradice la hipótesis de este trabajo. Es decir, si los individuos no utilizan las tradicionales fuentes de financiamiento ( tanda $=$ prestamist $a=0$ ), entonces, ceteris paribus, se observa una mayor participación en las CAI. Sin embargo, debido a que éstas son un mecanismo de crédito y ahorro que coexiste con otras fuentes de financiamiento, se deben comparar estos aspectos respecto a las características que presentan las tandas y los préstamos por parte de familiares/amigos que comparten esta dualidad, mas no los prestamistas, quienes otorgan únicamente créditos.

Debido a que las tandas son un mecanismo de ahorro y crédito donde no se pagan ni se cobran intereses, los individuos motivados por querer ahorrar/invertir pudieran tener un mayor interés en participar en una CAI. Por el contrario, si el individuo quiere obtener un crédito, indudablemente la opción más económica es la tanda pero la misma estructura en cuanto al otorgamiento del crédito (rotativo y de acuerdo el turno correspondiente) pudiera no ser de mucha ayuda, prefiriendo así pertenecer a las CAI.

Las CAI y los prestamistas son mecanismos muy distintos; una persona para la obtención de un crédito posiblemente prefiera una CAI a un prestamista por la diferencia entre las tasas de interés cobradas y porque ésta no requiere de ninguna garantía. De esta forma, recurrirían a un prestamista únicamente los individuos que no son miembros de una CAI, o que aun siéndolo requieran de una mayor cantidad de recursos, o porque ya obtuvieron un préstamo por parte de la CAI.

Para confirmar estos resultados se estimó el modelo número dos, en el cual las variables tanda, prestamista y préstamo-familia fueron sustituidas por los montos monetarios que los hogares obtuvieron por parte de cada fuente de financiamiento (tanda-monto, prestamista-monto y préstamofamilia-monto). En este modelo todas las variables resultaron significativas, sin que ocurrieran cambios significativos en los resultados; las únicas excepciones consisten en terrenos-propios que en este caso no es significativa y préstamo-familia-monto significativa a $10 \%$. De acuerdo a las 
estimaciones, si el individuo obtuvo los recursos por medio de los tradicionales mecanismos de financiamiento, tendrá un menor incentivo en participar en las CAI. Por lo anterior, se desprende que la participación en las CAI será más probable en la medida en la que los individuos no utilicen las tandas, familiares/amigos o prestamistas como fuente de recursos; en este sentido las CAI no estarían sustituyendo estas fuentes sino que constituirían un medio alternativo, en ausencia del sector financiero formal, para la obtención de créditos y el depósito de los ahorros.

\section{Conclusiones}

En los últimos años el énfasis que las microfinanzas han recibido a nivel mundial se justifica por la provisión de servicios de ahorro y crédito para los individuos excluidos del sector financiero formal. En la localidad de Santo Tomás Hueyotlipan, ante la ausencia de intermediarios financieros formales, los individuos parecen resolver sus necesidades de recursos a través de los tradicionales sistemas de financiamiento de las zonas rurales: tandas, préstamos de familiares/amigos y prestamistas. No obstante, los resultados de este estudio apuntan a que las cajas de ahorro informales, probablemente porque constituyen una alternativa más atractiva al proporcionar servicios tanto de ahorro como de otorgamiento de créditos a mejores condiciones, complementan la oferta de servicios financieros en la comunidad atrayendo aquellos individuos que no recurren a otro tipo de intermediarios. Estos resultados dejan entrever cierto optimismo sobre el rol de las CAI, ya que para los habitantes en esta localidad su presencia estaría representando una mejor posibilidad de acceso al ahorro y crédito respecto a los tradicionales sistemas informales de financiamiento que, no obstante, siguen estando a disposición de la comunidad.

Aún cuando las CAI no se enfocan hacia un género ni hacia los trabajadores de un sector en particular, su alcance sigue siendo limitado porque aquellas personas que carecen de ahorros son prácticamente excluidas de estas asociaciones al no poder cumplir con los compromisos inherentes a la membresía y que consisten en, además de poder ahorrar, hacerlo de forma regular.

Esto refrenda que los esquemas microfinancieros no logran proporcionar sus servicios a los individuos que se encuentran en la base de la pirámide. Desafortunadamente, estos individuos u hogares resultan particularmente vulnerables (Robinson, 2001) y para ellos no hay otra alternativa que continuar dependiendo de los préstamos por parte de familiares y amigos o recurrir a los prestamistas locales.

Con base en lo anterior, la presencia de las CAI en el municipio de Santo Tomás Hueyotlipan constituye un acceso alternativo a los servicios 
financieros para los individuos con menores ingresos condicionado a que las personas posean capacidad de ahorro. Éstos últimos en particular, estarían utilizando las cajas de ahorro informal como un medio para resguardar sus recursos debido, posiblemente, a que éstas proporcionan un servicio más económico -sobre todo en términos de costos y tiempo de traslado- que el que ofrecen los intermediarios financieros formales. En este mismo sentido, nuestros resultados apoyan lo señalado por parte del Consultative Group to Assist the Poor (CGAP) (Christen et al., 2003) al reconocer que estas organizaciones con alcance local constituyen y promueven un medio para el ahorro y el crédito.

\section{Bibliografía}

Adams, Dale, Douglas Graham y John D. Von Pischke (1984), Undermining rural development with cheap credit, Westview Press, Boulder, Colorado.

Agénor, Pierre-Richard, Peter Montiel y Nadeem Haque (1993), Informal financial markets in developing countries, a macroeconomic analysis, Blackwell Publishers, Oxford \& Cambridge.

Allen, Hugh (2007), "Finance begins with savings, not loans", en Thomas Dichter y Malcolm Harper (eds.), What's wrong with microfinance?, Intermediate Technology Publications Ltd., Bourton on Dunsmore, pp. 49-59.

Alpízar, Carlos y Claudio González-Vega (2006a), "El sector de las microfinanzas en México", Proyecto AFIRMA, sección V, UsAID, México.

Alpízar, Carlos, Malena Svarch y Claudio González-Vega (2006b), “El entorno y la participación de los hogares en los mercados de crédito en México", Proyecto AFIRMA, sección VII, UsAID, México.

Ardener, Shirley (1964), "The comparative study of rotating credit associations", Journal of the Royal Anthropological Institute, 94 (2), Wiley, London, pp. 201-229.

Aryeetey, Ernest (1995), Filling the niche: Informal finance in Africa, African Economic Research Consortium, Nairobi. 
Aryeetey, Ernest y Christopher Udry (1994), "The characteristics of informal financial markets in Africa", ponencia presentada al African Economic Research Consortium, diciembre 1994, Nairobi.

Bali-Swain, Ranjula (2002), "Credit rationing in rural india", Journal of Economic Development, 27 (2), Elsevier, Amsterdam, pp.1-20.

Bateman, Milford (2010), Why doesn't microfinance work? The destructive rise of local neoliberalism, Zed Books, London.

Bell, Clive (1990), "Interactions between institutional and informal credit agencies in rural India", The World Bank Economic Review, 4 (3), Oxford University Press, Oxford, pp. 297-327.

Besley, Timothy, Stephen Coate y Glenn Loury (1993), "The economics of rotating savings and credit associations", The American Economic Review, 83 (4), American Economic Association, Nashville, pp. 792-810.

Binswanger, Hans y Shahidur Khandker (1992), "The impact of formal finance on the rural economy of India", Policy Research Working Paper, no. 949, The World Bank, Washington, DC.

Bouman, Fritz y Otto Hospes (1994), Financial landscapes reconstructed: The fine art of mapping development, Westview Press, Boulder.

Bouquet, Emmanuelle (2007), "Construir un sistema financiero para el desarrollo rural en México", <http://trace.revues.org/index575. html>, 22 de mayo de 2010.

Campos-Bolaño, Pilar (2005), El ahorro popular en México: acumulando activos para superar la pobreza, Centro de Investigación para el Desarrollo A.c., Porrúa, México.

Casolaro, Luca, Leonardo Gambacorta y Luigi Guiso (2006), "Regulation, formal and informal enforcement and the development of the household moan Market: Lessons from Italy", en Giuseppe Bertola, Richard Disney y Charles Grant (eds.), The economics of consumer credit, MIT Press, Cambridge, pp. 93-134. 
Christen, Robert, Timothy Lyman y Richard Rosenberg (2003), Microfinance consensus guidelines: Guiding principles on regulation and supervision of microfinance, CGAP-The World Bank, Washington, DC.

Clarke, Daniel y Stefan Dercon (2009), "Insurance, credit and safety nets for the poor in a world of risk", Working Paper no. 81, Department of Economics and Social Affairs, United Nations, New York.

CNBV (Comisión Nacional Bancaria y de Valores) (2009), Reporte de inclusión financiera, CNBV, México.

Conde-Bonfil, Carola (2001), ¿Depósitos o puerquitos? Las decisiones de ahorro en México, El Colegio Mexiquense-La Colmena Milenaria, Zinacantepec, México.

Conning, Jonathan y Christopher Udry (2005), "Rural financial markets in developing countries”, Center Discussion Paper no. 914, Economic Growth Center, Yale University, New Haven.

Cotler, Pablo (2003), Las entidades microfinanciera del México urbano, Universidad Iberoamericana, México.

Dalla-Pellegrina, Lucia (2008), "Illegal finance, interest rates and bank lending: The missing supply side of usury", Global Business and Economics Review, 10 (3), Inderscience Publishers, Geneve, pp. 265-283.

De Janvry, Alain y Elisabeth Sadoulet (2000), "Making investment in the rural poor into good business: New perspectives for rural development in Latin America”, ponencia presentada en la conferencia Developing the rural economy and reducing poverty in Latin America and the Caribbean, 24 de marzo, New Orleans.

Dercon, Stefan y Joachim de Weerdt (2006), "Risk-sharing networks and insurance against illness", Journal of Development Economics, 81 (2), Elsevier, Amsterdam, pp. 337-356.

Diagne, Aliou (1999), "Determinants of household access to and participation in formal and informal credit markets in Malawi", Food Consumption and Nutrition Division Discussion Paper no. 67, International Food Policy Research Institute, Washington, DC. 
Dichter, Thomas (2007), "Can microcredit make an already slippery slope more slippery? Some lessons from the social meaning of debt" en Thomas Dichter y Malcolm Harper (eds.), What's wrong with microfinance?, Intermediate Technology Publications Ltd., Bourton on Dunsmore, pp. 9-17.

Durston, John (2002), El capital social campesino en la gestión del desarrollo rural: Díadas, equipos, puentes y escaleras, Comisión Económica para América Latina y el Caribe, Santiago de Chile.

Fafchamps, Marcel (1992), "Solidarity networks in preindustrial societies: Rational peasants with a moral economy", Economic development and cultural change, 41 (1), University of Chicago Press, Chicago, pp. 147-174.

Fafchamps, Marcel y Susan Lund (2003), "Risk-sharing networks in rural Philippines", Journal of Development Economics, 71 (2), Elsevier, Amsterdam, pp. 261-287.

Fiebig, Michael, Alfred Hannig y Sylvia Wisniwski (1999), "Savings in the context of microfinance-State of knowledge", Working Group on Savings Mobilization, CGAP-BMZ-GTZ, Eschborn.

Floro, María Sagrario y Debraj Ray (1997), "Vertical links between formal and informal financial institutions", Review of Development Economics, 1 (1), Wiley-Blackwell, London, pp. 34-56.

Geertz, Clifford (1962), “The rotating credit association: A 'middle rung' in development", Economic Development and Cultural Change, 10 (3), University of Chicago Press, Chicago, pp. 241-263.

Ghate, Prabhu (1992), Informal finance. Some findings from Asia, Oxford University Press, Hong Kong.

Gómez-Soto, Franz y Claudio González-Vega (2006), "Formas de asociación cooperativa y su participación en la provisión de servicios financieros en las áreas rurales de México", Proyecto AFIRMA, sección IV, USAID, México.

González-Vega, Claudio (1998), "Servicios financieros rurales: Experiencias del pasado, enfoques del presente", Economics and Sociolo- 
gy Occasional Paper, no. 2530, Rural Finance Program, Ohio State University, Columbus.

González-Vega, Claudio (2004), "Rural financial markets in Mexico: Issues and options", Chemonics International Inc., Washington, DC.

Hoff, Karla y Joseph Stiglitz (1990), "Imperfect information and rural credit markets-Puzzles and Policy Perspectives", The World Bank Economic Review, 4 (3), Oxford University Press, Oxford, pp. 235-250.

Hulme, David (2007), "Is microdebt good for poor people? A note on the dark side of microfinance", en Thomas Dichter y Malcolm Harper (eds.), What's wrong with microfinance?, Intermediate Technology Publications Ltd., Bourton on Dunsmore, pp. 19-22.

IDB (Inter-American Development Bank) (2004), Unlocking credit, the cuest for deep and stable bank lending, John Hopkins University Press, Washington, DC.

International Labour Organization (2006), Effectiveness of micro-finance programmes in reducing vulnerability to debt bondage in Andhra Pradesh, International Labour Office, Geneva.

Johnson, Susan y Ben Rogaly (1997), Microfinance and poverty reduction, Oxfam y Actionaid, Oxford.

Karmakar, Krishna Gopal (1999), Rural credit and self-help groups, Sage Publications, New Delhi.

Klein, Emilio (2009), Condicionantes laborales de la pobreza rural en América Latina, Food and Agriculture Organization, Santiago de Chile.

Kovsted, Jens y Peter Lyk-Jensen (1999), "Rotating savings and credit association: The choice between random and bidding allocation of funds", Journal of Development Economics, 60 (1), Elsevier, Amsterdam, pp. 143-172.

Lamberte, Mario (1988), “The urban informal credit markets: An integrative Report”, Working Paper Series no. 1988-25, Philippine Institute for Development Studies, Makati, Metro-Manila. 
Ledgerwood, Joanna (1999), Microfinance handbook: An institutional and financial perspective, World Bank, Washington, DC.

Lieberman, Morton (1979), "Help seeking and self-help groups", en Morton Lieberman y Leonard Borman, Self-help groups for coping with crisis, Jossey-Bass Inc. Publishers, San Francisco, pp. 116-149.

Lomnitz, Larissa (1975), Cómo sobreviven los marginados, Siglo XxI editores, México.

Lorenz, Edward (1991), "Neither friends nor dtrangers: Informal networks of subcontracting in french industry", en Grahame Thompson, Jennifer Frances, Rosalind Levacic y Jeremy Mitchell (eds.), Markets, hierarchies and networks: The coordination of social life, Sage Publications-Open University, London, pp. 183-192.

Mansell-Carstens, Catherine (1995), Las finanzas populares en México: el redescubrimento de un sistema financiero olvidado, Centro de Estudios Monetarios Latinoamericanos- Editorial Milenio-Instituto Tecnológico Autónomo de México, México.

McKinnon, Ronald (1973), Money and capital in economic development, Brookings Institution, Washington, DC.

Morduch, Jonathan (1999), "Between the state and the market: Can informal insurance patch the safety net?", The World Bank Research Observer, 14 (2), Oxford University Press, Oxford, pp. 187-207.

Nagarajan, Geetha y Richard Meyer (2005), "Rural finance: Recent advances and emerging lessons, debates, and opportunities", Reformatted version of Working Paper, Department of Agricultural, Environmental, and Development Economics, Ohio State University, Columbus.

Okurut, Nathan, Andrie Schoombee y Servaas van der Berg (2004), "Credit demand and credit rationing in the informal financial sector in Uganda", ponencia presentada en la conferencia African Development and Poverty Reduction: The Macro-Micro Linkage, 13-15 de octubre, Somerset West.

Padia, Veena (2005), "Social mobilization and micro-credit for women's empowerment: A study of the DHAN Foundation", en Neera 
Burra, Joy Deshmukh-Ranadive y Ranjani K. Murthy (eds.), Micro-credit, poverty and empowerment. Linking the triad, Sage Publications India Pvt. Ltd., New Delhi, pp. 161-199.

Raccanello, Kristiano (2008), "El financiamiento informal de la salud en San Andrés Cholula, Puebla. Un estudio exploratorio", en Norma González González, Martha Isabel Ángeles Constantino y Fernando Cruz (coords.), Salud, sociedad y democracia, Plaza y Valdés, México, pp.119-144.

Raccanello, Kristiano, Jayant Anand y Patricia Arroyo Martínez (2009), "Social capital as an incentive for participation and formation of women-dominant ROSCAs", en Donald Wood (ed.), Economic development, integration, and morality in Asia and the Americas. Research in economic anthropology, vol. 29, Bingley, Emerald, pp. 407-429.

Rajivan, Anuradha (2005), “Micro-credit and women's empowerment: A case study of SHARE micro-finance limited", en Neera Burra, Joy Deshmukh-Ranadive y Ranjani K. Murthy (eds.), Microcredit, poverty and empowerment. Linking the triad, Sage Publications India Pvt. Ltd., New Delhi, pp. 116-160.

Rodríguez-Vázquez, Verónica Patricia (2010), “Mapa del microfinaciamiento en México" en Verónica Patricia Rodríguez Vázquez y David Camino Blasco (eds.), Un acercamiento a la eficiencia del microfinanciamiento en México, Fundación Universidad de las Américas Puebla, Puebla, pp. 19-69.

Robinson, Marguerite (2001), The microfinance revolutions. Sustainable finance for the poor, World Bank-Open Society Institute, Washington, DC.

Rutherford, Stuart (2000), The poor and their money, Oxford University Press \& Department for International Development, New Delhi.

Sagarpa y Secretaría de Desarrollo Rural del Estado de Puebla. (2006), "Diagnóstico municipal con participación social Santo Tomás Hueyotlipan 2006", Consejo Municipal de Desarrollo Rural Sustentable, Puebla, <http://www.sdr.gob.mx/Contenido/informacion $\% 20$ municipal/ddr7/diagnosticos/dsthueyotlipan.pdf>, 15 de abril 2010. 
Schrader, Heiko (1996), "Informal finance and intermediation", Working Paper no. 252, Faculty of Sociology, University of Bielefeld, Bielefeld.

Shaw, Edward (1973), Financial deepening in economic development, Oxford University Press, New York.

Stiglitz, Joseph y Andrew Weiss (1981), "Credit rationing in markets with imperfect information", The American Economic Review, 71 (3), American Economic Association, Nashville, pp. 393-410.

Stoller, Eleanor y Karen Pugliesi (1991) "Size and effectiveness of informal helping networks: A panel study of older people in the community", Journal of Health and Social Behavior, 32 (2), Sage Publications, Austin, pp. 180-191.

Tejerina, Luis y Glenn Westley (2007), "Financial services for the poor: household survey sources and gaps in borrowing and savings", Sustainable Development Department Technical Paper Series, Inter-American Development Bank, Washington, DC.

Van Bastelaer, Thierry (2000), "Does social capital facilitate the poor's access to credit? A review of the microeconomic literature", Social Capital Initiative Working Paper no. 8, World Bank, Washington, DC.

Van Staveren, Irene (2002), "Global finance and gender", en Jan Aart Scholte y Albrecht Schnabel (eds.), Civil Society and Global Finance, Routledge, London, pp. 228-246.

Vélez-Ibáñez, Carlos (1983), Bonds of mutual trust. The cultural systems of rotating credit associations among urban mexicans and chicanos, Rutgers University Press, New Brunswick.

Vélez-Ibáñez, Carlos (2010), An impossible living in a transborder world: Culture, confianza, and economy of mexican-origin populations, The University of Arizona Press, Tucson.

Woolcock, Michael (1998), "Social capital and economic development: Toward a theoretical synthesis and policy framework", Theory and Society, 27 (2), Springer, Dordrecht, pp.151-208. 
шв (World Bank) (2001), World Development Report 2000/2001-Attacking Poverty, World Bank, Washington, DC.

Yunus, Muhammad (2003), Banker to the poor: Micro-lending and the battle against world poverty, Public Affairs, New York.

Zapata-Martelo, Emma, Verónica Vázquez-García, Pilar Alberti Manzanares, Elia Pérez Nasser et al. (2003), Microfinanciamiento y empoderamiento de mujeres rurales. Las cajas de ahorro y crédito en México, Colegio de Postgraduados-Fideicomiso del Programa Nacional de Financiamiento al Microempresario-Plaza y Valdés, México.

Zeller, Manfred (1994), "Determinants of credit rationing: A study of informal lenders and formal credit groups in Madagascar", Food Consumption and Nutrition Division Discussion Paper no. 2, International Food Policy Research Institute, Washington, DC.

Zeller, Manfred y Richard Meyer (2002), The triangle of microfinance: Financial sustainability, outreach and impact, John Hopkins University Press, Baltimore.

Recibido: 4 de junio de 2010. Reenviado: 28 de junio de 2011. Reenviado: 10 de noviembre de 2011. Aceptado: 15 de marzo de 2012.

Kristiano Raccanello. Es doctor en economía por la Fundación Universidad de las Américas Puebla, México, donde es profesor-investigador del Departamento de Economía desde 1999. Desde más de 10 años colabora regularmente con el Banco de Guatemala y ha efectuado análisis e investigaciones por distintas entidades microfinancieras en México. Es miembro del Sistema Nacional de Investigadores, nivel I. Su línea de investigación actual se enfoca en los mercados financieros informales, microfinanzas y créditos predatorios. Entre sus últimas publicaciones destacan, en coautoría: "Rational vs. heuristic motives. What matters when redeeming the pledge?" en Advances in Behavioral Finance \& Economics 1 (2), Spring, Los Angeles, pp. 17-42 (2011); "Collateral ownership and women's participation in informal finance schemes" en International Journal of Microfinance, 1 (1), Pondicherry University, Tamil Nadu, India pp. 14-24 (2011). 
Gerardo Roldán-Bravo. Es licenciado en economía por la Fundación Universidad de las Américas Puebla, México. Ha colaborado en la realización de estudios de campo en el medio rural incluyendo el levantamiento de datos e investigación económica; durante el 2008 se ha desempeñado como analista de presupuesto en la Dirección de Presupuesto de la Secretaría de Finanzas del Estado de Puebla y desde 2009 trabaja en Tenaris Tamsa. 